\title{
Comment on Frechen et al. "Late Pleistocene fluvial dynamics in the Hochrhein Valle and in the Upper Rhine Graben: chronological frame"
}

\author{
Frank Preusser $\cdot$ Stéphane Kock $\cdot$ Helena Rodnight
}

Received: 11 June 2010/Accepted: 30 December 2010/Published online: 11 February 2011

(C) Springer-Verlag 2011

The River Rhine connects the areas of the Alpine and Scandinavian glaciation and follows part of the European Cenozoic Rift System (cf. Preusser 2008). As a consequence, deposits of the River Rhine are important archives for reconstructing both the environmental and the tectonic history along one of the most heavily populated regions of our planet. Establishing chronologies for fluvial deposits of the Quaternary period has become available through the dating of sediment deposition ages using optically stimulated luminescence (OSL) (cf. Wallinga 2002a). In this context, the paper by Frechen et al. (2010), as well as the related publication by Lämmermann-Barthel et al. (2009), is a contribution towards a better understanding of forcing factors behind deposition and incision in fluvial systems. However, we have observed one crucial flaw in the experimental design, which has probably led to a significant overestimation of the OSL ages reported by Frechen et al. (2010) and thus consequently led Lämmermann-Barthel et al. (2009) to an inappropriate interpretation of the fluvial dynamics. These findings are in conflict with studies by Kock

F. Preusser

Institut für Geologie, Universität Bern, Baltzerstrasse $1+3$, 3012 Bern, Switzerland

Present Address:

F. Preusser $(\bowtie)$

Department of Physical Geography and Quaternary Geology, Stockholm University, 10691 Stockholm, Sweden

e-mail: frank.preusser@natgeo.su.se

S. Kock

Geologisch-Paläontologisches Institut, Universität Basel, Bernoullistrasse 32, 4056 Basel, Switzerland

H. Rodnight

Institute for Geology and Palaeontology, University

of Innsbruck, Innrain 52, 6020 Innsbruck, Austria et al. (2009a, b) that yield significantly younger age estimates and hence a different reconstruction of the fluvial dynamics in the Hochrhein Valley. Interestingly, both research groups have partly investigated the same outcrops. In the following, we will explain why we consider the data and interpretations of Kock et al. (2009a, b) to be more reliable.

Both research groups logged fluvial deposits in several gravel pits and used OSL dating to determine sediment deposition ages (see Preusser et al. 2008, 2009 for methodological review). OSL ages are in both studies determined using the single-aliquot regenerative dose (SAR) approach applied to sand-size quartz grains (mainly 150-200 $\mu \mathrm{m}$ ). Frechen et al. (2010) additionally applied multiple aliquot additive dose (MAAD) and SAR methodology to K-feldspar but state that they interpret the feldspar data as being less reliable. For quartz, both research teams have carried out a number of performance tests to identify the measurements parameters and used a similar set-up (preheat at 240 and $230^{\circ} \mathrm{C}$, respectively). Thus, the methodology used for age determination is almost identical. However, there is one small but important difference in the experimental design. While Frechen et al. (2010) used aliquots with a size of $8 \mathrm{~mm}$ and calculated the age from the weighted mean of repeated measurements, Kock et al. (2009a) preferred 2-mm aliquots and the minimum age model (MAP) of Preusser et al. (2007) that was developed and tested for pro-glacial sediments from the Swiss lowlands. The size of the aliquots controls the number of grains being measured, $>1000$ from $8 \mathrm{~mm}$ and about 100 for $2 \mathrm{~mm}$ (Lomax et al. 2003). Explaining why this difference is of crucial importance for the accuracy of OSL ages requires a short introduction into the principles of the method.

OSL dating utilises a light-sensitive signal in quartz grains that is erased during sediment transport, when the grains are exposed to the light of the sun. During burial, 
when the grains are sealed from daylight, the latent OSL signal rises due to the interaction of environmental radioactivity with the crystal lattice. For dating, samples are taken without exposing them to light (i.e. sampling by metal tubes), and the OSL intensity is quantified by comparison with known given doses. This procedure is known as determination of the equivalent dose $\left(\mathrm{D}_{\mathrm{e}}\right)$. The presently used SAR approach has the advantage, compared with MAAD methodology, that each individual measurement is made on the same grains (aliquot) and that it is easily possible to carry out repeated $D_{e}$ determinations for the same sample. However, the prerequisite for dating, the assumption that the OSL signal was set to zero at the time of deposition, is not always fulfilled when dating fluvial and in particular glaciofluvial deposits (e.g., Rodnight et al. 2006; Fiebig and Preusser 2007; Preusser et al. 2007). If the OSL signal was not zeroed during sediment transport, it will add a residual onto the signal accumulated during burial, and therefore lead to overestimation of the real burial dose and hence age.

It has to be considered that in natural environments, each grain will have its own sedimentation history, i.e. individual grains in sediments will have been exposed to light for different times. Modern poorly bleached sediments hence comprise grains that have different residual levels at deposition, ideally including a portion of grains in which the OSL signal was set to zero. This phenomenon is known as differential bleaching (Duller 1994). During burial, more latent signal is induced in the grains but not all grains receive the same dose due to the inhomogeneous distribution of radioactivity in sediments (cf. Mayya et al. 2006; Rufer and Preusser 2009) and other systematic and random sources of variation (Galbraith et al. 2005). As a consequence, it is not possible to just use the lowest $D_{e}$ value determined for a sample but it is necessary to apply more complex statistical approaches, so-called minimum age models (e.g., Galbraith et al. 1999; Bailey and Arnold 2006; Preusser et al. 2007; Rodnight 2008).

It is important to note that the OSL signal used for $\mathrm{D}_{\mathrm{e}}$ determination should originate from a single grain because otherwise the signal of completely and incompletely bleached grains will be mixed. The resulting overestimation of OSL ages has been demonstrated by both computer simulations (Wallinga 2002b) as well as by applying single grain methodology (Duller 2004, 2006, 2008). However, the OSL output of individual grains is highly variable, and only a small fraction of the grains (usually 1-2\%, Duller 2004) will dominate the signal from multiple-grain aliquots. Thus, small aliquots with less than about 100 grains will mimic single grain measurements for most samples while avoiding methodological problems associated with the latter approach.

The suitability of small aliquot quartz SAR methodology applied for the dating of fluvial and glaciofluvial sediments has been demonstrated, for example, by Choi et al. (2007) for the Lower Terrace of River Rhine in the Middle Rhine area and by Preusser et al. (2007) for proglacial sediments in the Swiss lowlands. For these two test studies, direct age control is available through the presence of the Laacher See Tephra (dated to $12.9 \mathrm{ka}$ ) and radiocarbon dating. Both studies clearly demonstrate that using the mean of a $D_{e}$ distribution results in significantly overestimated OSL ages. For example, Preusser et al. (2007) report OSL ages for the Hüntwangen pit (in the eastern part of the Hochrhein Valley) of up to $40 \mathrm{ka}$ using the arithmetic mean for a horizon dated by radiocarbon to younger than $30 \mathrm{ka}$. In comparison, applying minimum age models results in ages between 30 and $25 \mathrm{ka}$.

For the Hochrhein Valley, Kock et al. (2009a) have shown that the central tendency approach gives significantly higher $D_{e}$ estimates than those derived through minimum age approaches (Fig. 1). Considering the experience from dating known-age samples (Choi et al. 2007; Preusser et al. 2007), the higher ages derived for mean are interpreted to result from differential bleaching of the OSL signal; hence, the results derived through minimum age approaches are regarded more reliable.

We demonstrate this for two outcrops investigated by both research teams (that are differently named in the

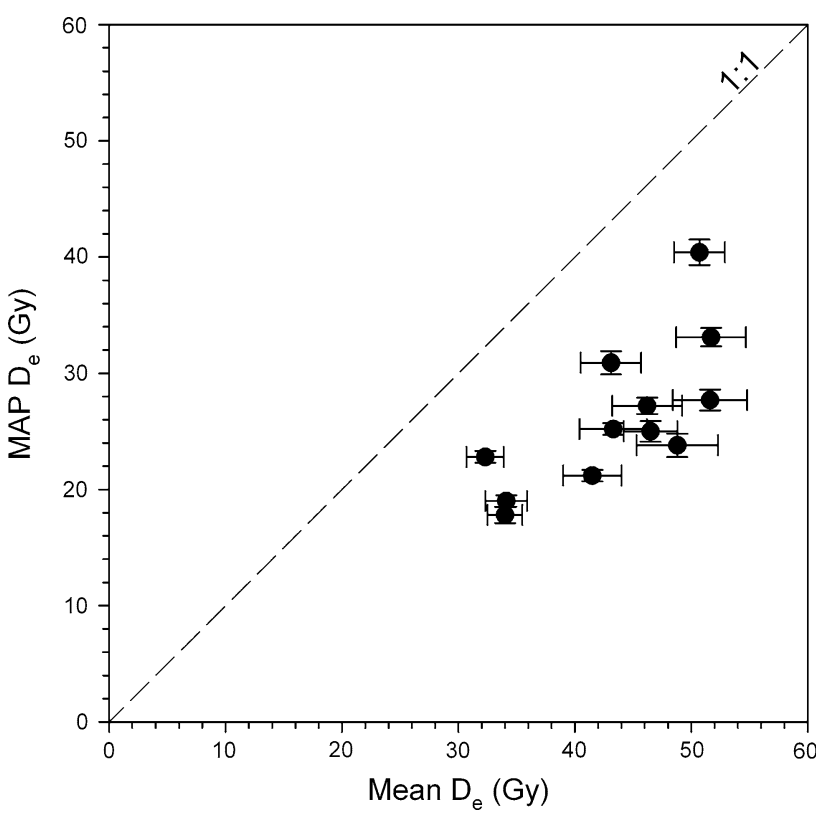

Fig. 1 Plot of $D_{e}$ values for samples HRT1-12 of Kock et al. (2009a) calculated using arithmetic mean and the minimum age model of Preusser et al. (2007) (MAP), respectively. Using the latter approach, developed and tested for pro-glacial sediments from the Swiss lowlands gives systematically lower $\mathrm{D}_{\mathrm{e}}$ values. Studies by Choi et al. (2007) and Preusser et al. (2007) have shown for Late Pleistocene samples that OSL ages calculated using the MAP values agree well with independent age control. OSL ages determined using this approach are hence regarded more reliable 
publications). For the Markhof (Herten) quarry, photographic documentation implies that the same horizon has been sampled and dated (Fig. 12 of Kock et al. 2009b; Fig. 5 of Frechen et al. 2010). Frechen et al. (2010) yield OSL ages of $46.4 \pm 4.1 \mathrm{ka}$ (HER1) and $37.3 \pm 7.4 \mathrm{ka}$ (HER2) but Kock et al. (2009a) report an age of $16.8 \pm 1.0 \mathrm{ka}$ (HRT6) for this horizon. For the gravel pit in Haltingen (Hupfer), Frechen et al. (2010) report three OSL ages around $35 \mathrm{ka}$ (HUP1-3) and Kock et al. (2009a) yield three ages younger than $22 \mathrm{ka}$ (HRT7-9). For the stratigraphically lowermost sample HRT7 of Kock et al. (2009a), the MAP age is $20.9 \pm 1.2 \mathrm{ka}$ but calculating the mean for this particular sample would give an age of $35.6 \pm 3.0 \mathrm{ka}$. We have also applied different statistical approaches for this sample and get identical $D_{e}$ values for MAP $(27.2 \pm 0.7 \mathrm{~Gy})$ as well as for the minimum age model $(27.8 \pm 4.6 \mathrm{~Gy})$ and the finite mixture model $(27.7 \pm 3.0$ Gy) (cf. Galbraith et al. 1999; Roberts et al. 2000). This consistency gives us good confidence for the reliability of the different statistical approaches.

From the above, we conclude that the ages reported by Frechen et al. (2010) should be considered only as maximum estimates due to likely overestimation resulting from differential bleaching of the OSL signal. It appears that the approach used by Kock et al. (2009a,b) reflects the more likely real deposition age of the samples. The major implication is that the concept of sedimentary dynamics discussed by Lämmermann-Barthel et al. (2009) is not based on a solid chronological framework. Furthermore, we do not follow the statement by Frechen et al. (2010) that “... age overestimation in large river systems seems to be normally small". This statement is probably correct for Holocene deposits of River Rhine and maybe even for Pleistocene sediments from sites further downstream. However, the Hochrhein Valley and southern Upper Rhine Graben were only a few tens of kilometres from the ice margin during the latest Pleistocene. In such environments, as demonstrated for the Swiss lowland (Preusser et al. 2007), differential bleaching can have a strong effect and needs to be carefully investigated when using OSL for the dating of such glaciofluvial sediments.

\section{References}

Bailey RM, Arnold LJ (2006) Statistical modelling of single grain quartz De distributions and an assessment of procedures for estimating burial dose. Quat Sci Rev 25:2475-2502

Choi SW, Preusser F, Radtke U (2007) Dating of river Rhine Lower Terrace sediments from the Middle Rhine area, Germany. Quat Geochron 2:137-142

Duller GAT (1994) Luminescence dating of poorly bleached sediments from Scotland. Quat Sci Rev 13:521-524
Duller GAT (2004) Luminescence dating of Quaternary sediments: recent advances. J Quat Sci 19:183-192

Duller GAT (2006) Single grain optical dating of glacigenic deposits. Quat Geochron 1:296-304

Duller GAT (2008) Single-grain optical dating of Quaternary sediments: why aliquot size matters in luminescence dating. Boreas 37:589-612

Fiebig M, Preusser F (2007) Investigating the amount of zeroing in modern sediments of River Danube, Austria. Quat Geochron 2:143-149

Frechen M, Ellwanger D, Hinderer M, Lämmermann-Barthel J, Neeb I, Techmer A (2010) Late Pleistocene fluvial dynamics in the Hochrhein Valley and in the Upper Rhine Graben: chronological frame. Int J Earth Sci 99:1955-1974

Galbraith RF, Roberts RG, Laslett GM, Yoshida H, Olley JM (1999) Optical dating of single and multiple grains of quartz from Jinmium rock shelter, northern Australia: Part I, Experimental design and statistical models. Archaeometry 41:339-364

Galbraith RF, Robertsb RG, Yoshidab H (2005) Error variation in OSL palaeodose estimates from single aliquots of quartz: a factorial experiment. Rad Meas 39:289-307

Kock S, Kramers JD, Preusser F, Wetzel A (2009a) Dating of Late Pleistocene deposits of River Rhine using Uranium series and luminescence methods: potential and limitations. Quat Geochron 4:363-373

Kock S, Huggenberger P, Preusser F, Rentzel P, Wetzel A (2009b) Formation and evolution of the Lower Terrace of the Rhine River in the area of Basel. Swiss J Geosci 102:307-321

Lämmermann-Barthel J, Hinderer M, Neeb I, Frechen M (2009) Late glacial to Holocene fluvial aggradation and incision in the southern Upper Rhine Graben-climatic and tectonic controls. Quatenaire 20:24-34

Lomax J, Hilgers A, Wopfner H, Grün R, Twidale CR, Radtke U (2003) The onset of dune formation in the Strzelecki Desert, South Australia. Quat Sci Rev 22:1067-1076

Mayya YS, Mortekai P, Murari MK, Singhvi AK (2006) Towards quantifying beta microdosimetric effects in single-grain quartz dose distribution. Rad Meas 41:1032-1039

Preusser F, Blei A, Graf HR, Schlüchter C (2007) Luminescence dating of Würmian (Weichselian) proglacial sediments from Switzerland: methodological aspects and stratigraphical conclusions. Boreas 36:130-142

Preusser F, Degering D, Fuchs M, Hilgers A, Kadereit A, Klasen N, Krbetschek M, Richter D, Spencer J (2008) Luminescence dating: Basics, methods and applications. Eiszeit Gegen (Quat Sci J) 57:95-149

Preusser F, Chithambo ML, Götte T, Martini M, Ramseyer K, Sendezera EJ, Susino GJ, Wintle AG (2009) Properties of quartz related to its use as a luminescence dosimeter. Earth Sci Rev 97:196-226

Roberts RG, Galbraith RF, Yoshida H, Laslett GM, Olley JM (2000) Distinguishing dose populations in sediment mixtures: a test of single-grain optical dating procedures using mixtures of laboratory-dosed quartz. Rad Meas 32:459-465

Rodnight H (2008) How many equivalent dose values are needed to obtain a reproducible distribution? Anc TL 26:3-10

Rodnight H, Duller GAT, Wintle AG, Tooth S (2006) Assessing the reproducibility and accuracy of optical dating. Quat Geochron $1: 109-120$

Rufer D, Preusser F (2009) Potential of autoradiography to detect spatially resolved radiation patterns in the context of trapped charge dating. Geochronometria 34:1-13

Wallinga J (2002a) Optically stimulated luminescence dating of fluvial deposits: a review. Boreas 31:303-322

Wallinga J (2002b) On the detection of age overestimation using single aliquot techniques. Geochronometria 21:17-26 